\title{
DINÂMICA DAS ÁGUAS NO SISTEMA RIO-PLANÍCIE DE INUNDAÇÃO DO RIO PARAGUAI EM CÁCERES - MATO GROSSO
}

\author{
Gustavo Roberto dos Santos Leandro ${ }^{(\mathrm{a})}$, Flávio Rodrigues do Nascimento $^{(\mathrm{b})}$, Célia Alves de \\ Souza $^{(\mathrm{c})}$
}

\begin{abstract}
(a) Doutoramento pelo Programa de Pós-Graduação em Geografia, Faculdade de Ciências e Tecnologia, Campus de Presidente Prudente da Universidade Estadual Paulista "Júlio de Mesquita Filho" - UNESP, Email: gustavogeociencias@hotmail.com

(b) Professor do Departamento de Geografia do Instituto de Geociências, Universidade Federal Fluminense UFF, Email: flaviogeo@bol.com.br

(c) Professora do Curso de Geografia da Faculde de Ciências Humanas, Campus de Cáceres da Universidade do Estado de Mato Grosso - UNEMAT, E-mail: celiaalvesgeo@globo.com
\end{abstract}

\section{EIXO: SISTEMAS GEOMORFOLÓGICOS: ESTRUTURA, DINÂMICAS E PROCESSOS.}

\section{Resumo}

O estudo foi realizado com o processamento de dados de precipitação anual, bem como da vazão e altura do rio - valores máximo, médio e mínimo de uma série histórica de 40 anos (1970 a 2010). Para tanto foram consultadas as estações de Cáceres - Mato Grosso (ANA e IFMT). O clima regional exerce influência no regime hidrológico do rio Paraguai. Contudo, a dinâmica de suas águas é condicionada não apenas pelo volume precipitado. Salienta-se o papel do relevo com o amortecimento da planície aluvial que influencia na concentração do volume de água. Nesse sentido, foram identificados quatro períodos hidrodinâmicos sendo os picos de Cheia entre Janeiro - Março, período de Vazante entre Julho - Setembro com intervalos de Enchimento (Outubro Dezembro) e Esvaziamento (Abril - Junho). Importante destacar que, mudanças na cobertura vegetal com os usos intensivos podem alterar as dinâmicas hidrológica e morfológica desse sistema.

Palavras-chave: interações hidromordinâmicas; conectividade; planície pantaneira; ambientes fluviais.

\section{Introdução}

As condições climáticas em Mato Grosso apresentam particularidades em dois períodos do ano. $\mathrm{Na}$ região Sudoeste de Mato Grosso tais condições influenciam a dinâmica hidrológica na bacia hidrográfica do Alto rio Paraguai. Associado aos arranjos geológico e geomorfológico, a fase de escoamento se expressa através da amplitude fluviométrica.

Segundo a classificação de Köppen, o Pantanal está inserido no grupo de Clima Tropical com estação seca ou clima de savana (Aw). Entre os principais mecanismos de precipitação destacam-se as chuvas convectivas, ocasionadas pelo aquecimento da superfície durante o dia (CAMARGO, 2011; PEREIRA et al. 2012). A temperatura média anual varia entre 22 e $26^{\circ} \mathrm{C}$, e a precipitação média anual é de 1.400 $\mathrm{mm}$, com variação entre 800 e $1.600 \mathrm{~mm}$. Os maiores índices pluviais são observados no Planalto. O período chuvoso estende-se de outubro a abril e concentra cerca de 70 a $80 \%$ da precipitação média anual (ANDRADE et al., 2012). 


\section{OS DESAFIOS DA GEOGRAFIA FÍSICA NA FRONTEIRA DO CONHECIMENTO \\ Instituto de Geociências - Unicamp \\ Campinas - SP \\ 28 de Junho à 02 de Julho de 2017}

$\mathrm{Na}$ bacia hidrográfica do Alto rio Paraguai, principal contribuinte para a dinâmica da planície pantaneira, a distribuição da pluviosidade média anual decresce no sentido Alto-Baixo Curso. Nas áreas de Planalto os valores variam entre 1.601-1800 mm enquanto que na Depressão do rio Paraguai esse valor varia entre 1401-1600 mm. Na região de Cáceres os valores anuais variam entre 1.201$1.400 \mathrm{~mm}$ reduzindo para $1001 \mathrm{~mm}$ em algumas áreas do Pantanal Inferior (CAMARGO, 2011). Desse modo, as cheias no Pantanal dependem diretamente das "Chuvas do Planalto". E, conforme há o escoamento e transporte pelos seus afluentes, este ambiente é inundado progressivamente como num efeito dominó.

Pesquisas e estudos têm demonstrado relações entre os volumes precipitados na região e a dinâmica de escoamento nos canais de drenagem da bacia do Alto rio Paraguai, sendo bem expressas no rio Paraguai e afluentes da margem direita. A interação entre o sistema canal-planície de inundação se tornou objeto de estudo por evidenciar o papel do pulso de inundação nos aspectos morfológicos e ecológicos no Complexo do Pantanal. A seguir, a consideração de alguns autores sobre o referido assunto.

Clarke et al. (2003) analisaram a variabilidade temporal do regime hidrológico na bacia do rio Paraguai; Grizio e Souza Filho (2010), no contexto climático e antrópico, avaliaram as alterações do regime de descarga do rio Paraguai no período entre 1966 e 2005 e compararam os resultados com os dados de precipitação da bacia; Santana et al. (2013) relacionaram o comportamento das séries temporais de pluviosidade e fluviosidade na bacia hidrográfica do rio Paraguai em três estações: Barra do Bugres, Cáceres e Descalvado, durante o período de 1980-2005; e Dallacort et al. (2014), por exemplo, propõe a discussão sobre a relação entre temperatura e o comportamento da precipitação pluviométrica anual e mensal no município de Cáceres/MT. Nesse sentido, o presente trabalho teve por objetivo identificar os períodos hidrodinâmicos do rio Paraguai na região de Cáceres - Mato Grosso e relacionar a dinâmica das águas aos aspectos morfológicos do sistema rio-planície de inundação.

\section{Material e métodos}

Para realização do estudo analisaram-se os dados consistidos das estações pluviométrica e fluviométrica de Cáceres pertencentes à rede hidrometeorológica da Agência Nacional de Águas (ANA). Localizada na cidade de Cáceres, Mato Grosso apresenta dados importantes sobre a dinâmica das águas. No presente estudo foram coletadas as informações referente ao período de 1970 a 2010 com ausência de dados de vazão após o ano de 2007.

Na Figura 1 está representada a área de estudo, onde foram destacados o sistema fluvial do rio Paraguai com seu sistema canal-planície de inundação e importantes unidades geomorfológicas como 
XVII Simpósio Brasileiro de Geografia Física Aplicada

I Congresso Nacional de Geografia Física

\section{OS DESAFIOS DA GEOGRAFIA FÍSICA NA FRONTEIRA DO CONHECIMENTO \\ Instituto de Geociências - Unicamp \\ Campinas - SP \\ 28 de Junho à 02 de Julho de 2017}

a Província Serrana e o Pantanal de Cáceres. Cabe salientar que o segmento configura importante transição e entrada para a planície pantaneira por convergir as águas provenientes das áreas elevadas da bacia do Alto rio Paraguai com destaque para a Chapada dos Parecis e Província Serra de Mato Grosso.

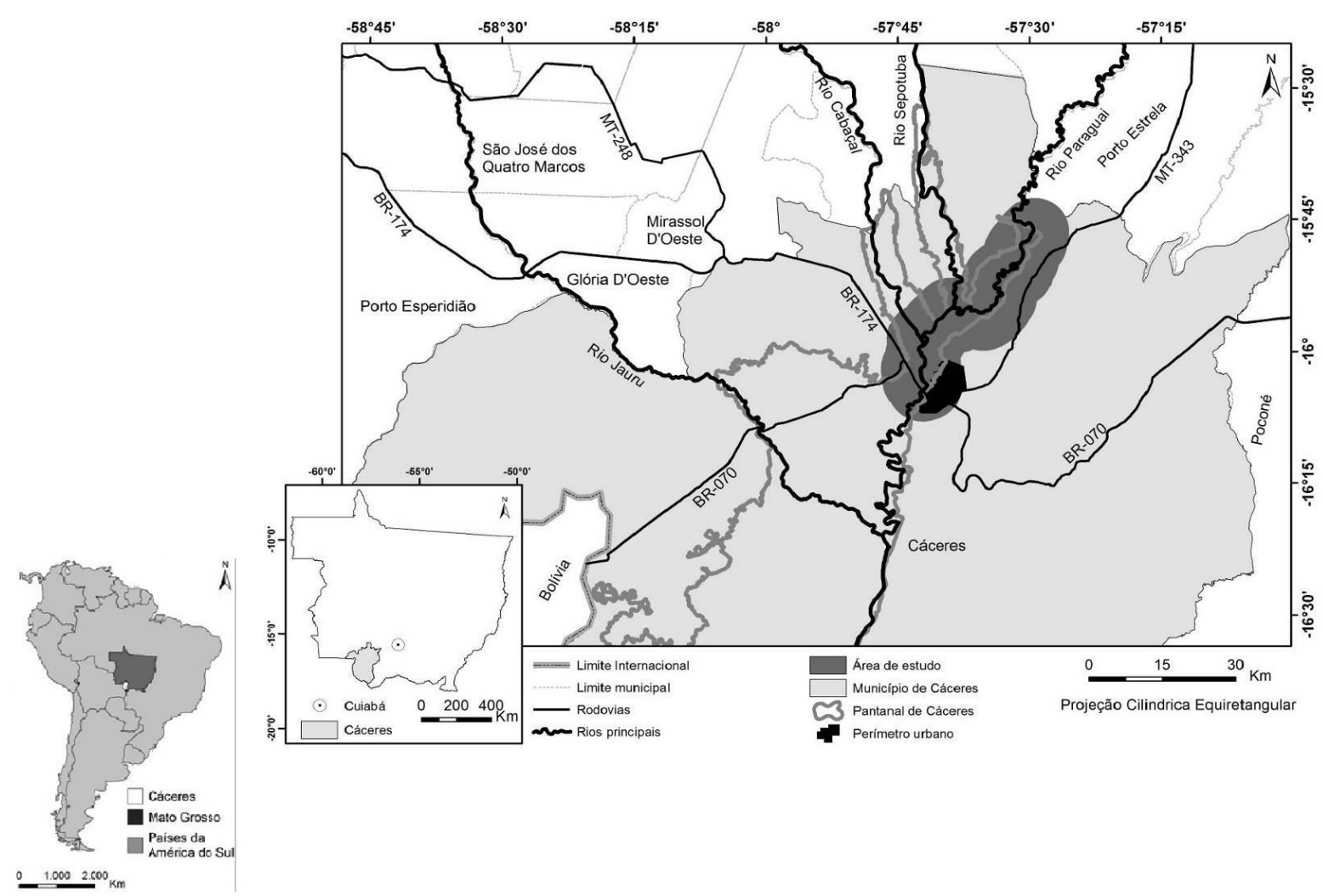

Figura 1. Localização da área de estudo no contexto do Pantanal Superior em Cáceres - Mato Grosso, Brasil. Org.: Gustavo Roberto dos Santos Leandro (2014).

Fonte: LEANDRO (2015).

E se tem, no Quadro 1, as informações referente as estações fluviométrica e pluviométrica.

\begin{tabular}{|c|c|c|c|c|c|c|c|}
\hline \multicolumn{9}{|c|}{ Estação Fluviométrica } & \multicolumn{3}{c|}{ Vazão m $^{\mathbf{3}} / \mathbf{s}^{-1}$} \\
\hline Nome & Código & Latitude/Longitude & Altitude & Área & Mínima & Média & Máxima \\
\hline Cáceres & 66070004 & $\begin{array}{c}16^{\circ} 03^{\prime} 47^{\prime} \text { ' S } \\
57^{\circ} 41^{\prime} 16^{\prime} \text { ' W }\end{array}$ & $110 \mathrm{~m}$ & $32.774 \mathrm{~km}^{2}$ & 133 & 537 & 2.659 \\
\hline \multicolumn{3}{|c|}{ Estação Pluviométrica } \\
\hline
\end{tabular}

Os registros sobre precipitação e vazão foram tabulados e representados em forma de gráficos onde constam volumes totais, as médias, máximas e mínimas. Os dados a respeito do rio Paraguai, entre outras informações, foram obtidos a partir de levantamento bibliográficos (livros, teses, dissertações e artigos). 
XVII Simpósio Brasileiro

de Geografia Física Aplicada

I Congresso Nacional

de Geografia Física

\section{OS DESAFIOS DA GEOGRAFIA FÍSICA NA FRONTEIRA DO CONHECIMENTO \\ Instituto de Geociências - Unicamp \\ Campinas - SP \\ 28 de Junho à 02 de Julho de 2017}

Os mapas temáticos - hipsométrico e de declividade - foram elaborados a partir de imagens do radar

SRTM. As imagens disponíveis para download no site da Embrapa - Brasil em Relevo, foram inseridas e manipuladas no programa ArcGis 9.3.

\section{Resultados e discussão}

O sistema fluvial do rio Paraguai é marcado por uma resposta lenta à precipitação, o que pode ser explicado pela forma da bacia, pela baixa declividade das vertentes, e pela grande capacidade de armazenamento das coberturas superficiais (GRIZIO-ORITA e QUEIROZ, 2013). No Pantanal de Cáceres, as mudanças na fisionomia da paisagem ocorrem associadas ao a) Controle Estrutural, b) Amplitude Fluviométrica, c) Dinâmica Sedimentológica e d) Morfodinâmica Atual. No período de cheia ocorre o transbordamento para a planície de inundação e no período de vazante, com a redução no volume de água e em decorrência da deposição de sedimentos, há alterações na configuração do corredor fluvial - canal e planície de inundação (Figura 2).

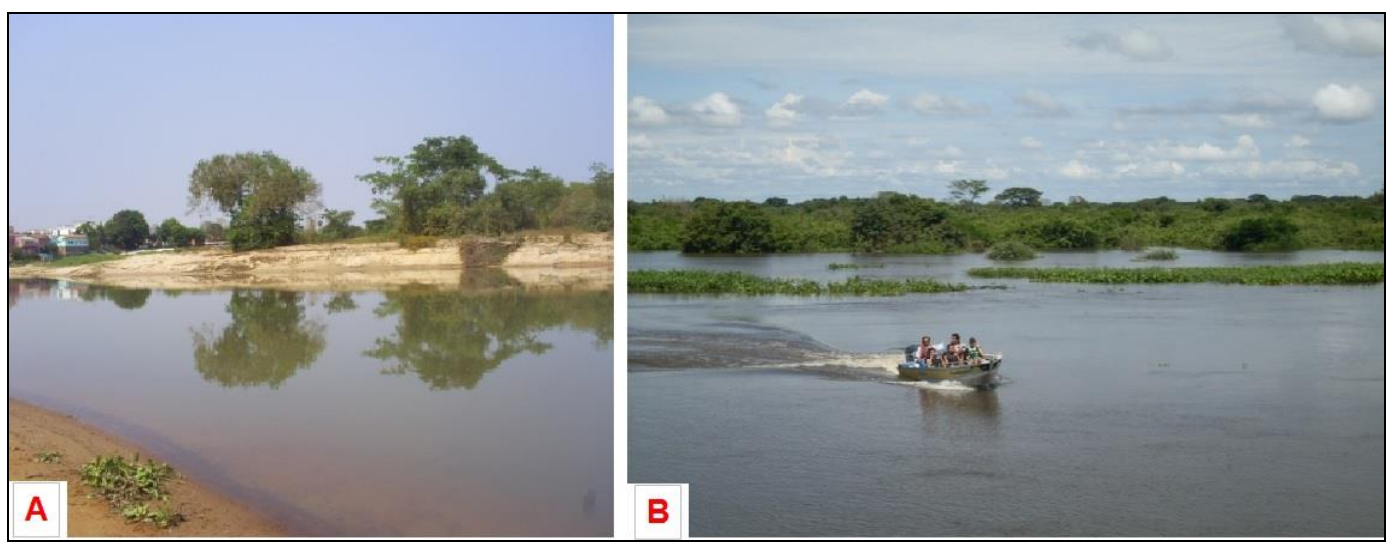

Figura 2. Ambiente fluvial denominado regionalmente de baía nos períodos de vazão mínima e máxima no rio Paraguai em Cáceres -Mato Grosso.

Fotos: Gustavo Roberto dos Santos Leandro (2012).

O contexto geológico e geomorfológico em Cáceres contribuem significativamente para a dinâmica do Pantanal Superior - se destaca a importância da Depressão do rio Paraguai e a Província Serrana, que delineia o sistema fluvial. Desse modo, os fatores declividade e elevação do terreno se destacam quando do armazenamento do volume de água e sua dinâmica, sendo expressas pela diversidade de ambientes fluviais e feições morfológicas (Figura 3). No trecho do rio Paraguai selecionado no presente estudo, o contato entre as Serras do Poção e Tarumã (Formação Raizama) com a planície de inundação (Formações Pantanal e Aluviões Atuais) controla a migração e o sentido do canal. Ou seja, o canal se defronta com a barreira geológica/geomorfológica (Figura 4). Tais fatores influenciam ainda os pulsos de inundação no sistema do canal principal e feições morfológicas ativas o que contribui 
para as mudanças e evolução dos ambientes fluviais. Os valores de declividade predominaram entre 0 a 3\% a exceção dos valores obtidos para a Província Serrana, superiores a 20\% (Figura 4).
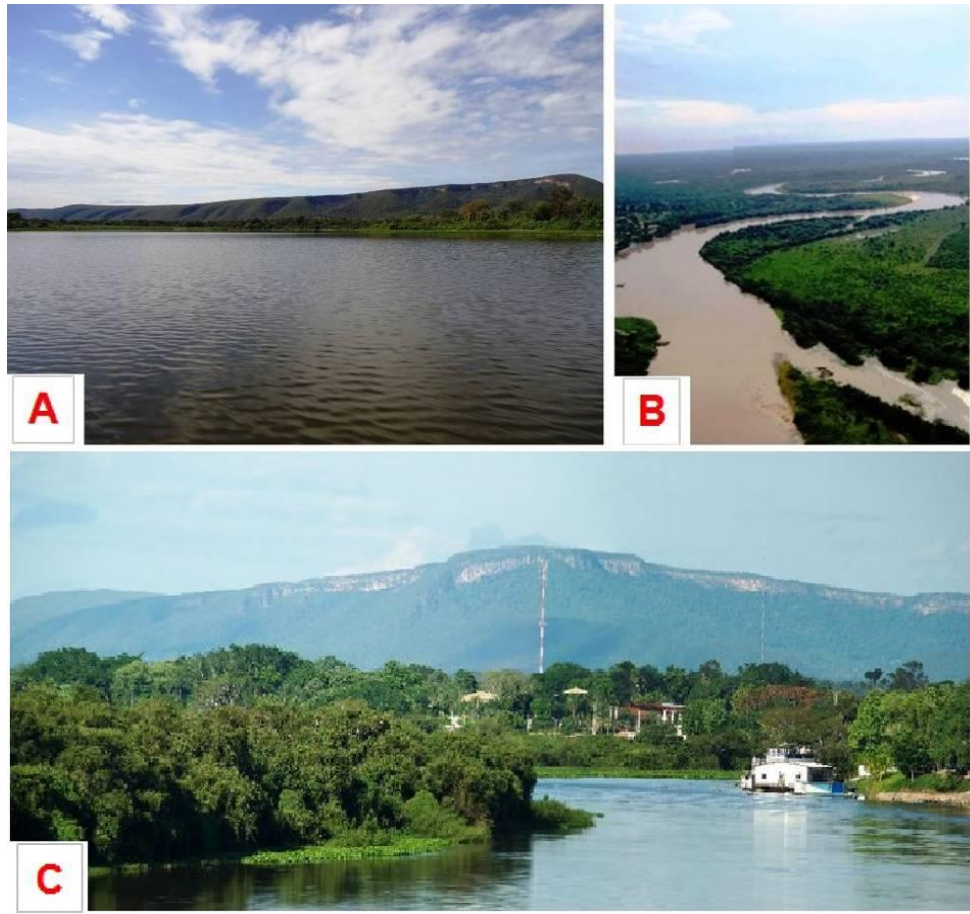

Figura 3. Aspectos gerais da Fisiologia na paisagem A) Serra do Poção B) Planície de inundação do rio Paraguai C) Rio Paraguai e planície de inundação, cidade de Cáceres e a Província Serrana Fotos: Gustavo Roberto dos Santos Leandro (2013).

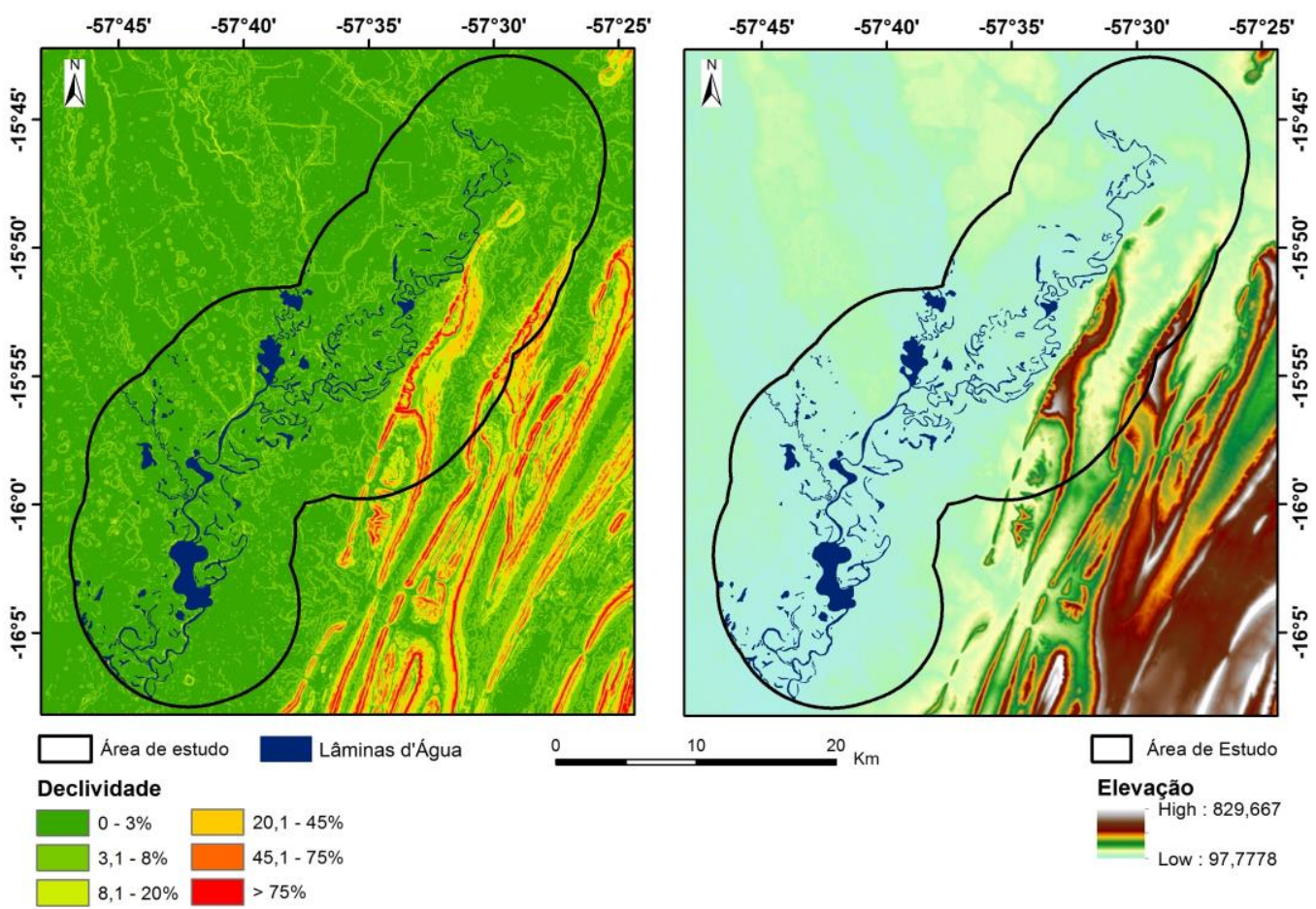

Figura 4. Gradiente hipsométrico na área de estudo com elevação gradual no terreno da Província Serrana a Leste.Fonte: Camargo (2011).Gustavo Roberto dos Santos Leandro (2014). 


\section{OS DESAFIOS DA GEOGRAFIA FÍSICA NA FRONTEIRA DO CONHECIMENTO \\ Instituto de Geociências - Unicamp \\ Campinas - SP \\ 28 de Junho à 02 de Julho de 2017}

Diante do contexto geológico/geomorfológico apresentado, a água precipitada e, que, aporta no sistema apresenta dinâmica em quatro períodos interanuais, sendo: a) Enchimento, b) Cheia, c) Esvaziamento e d) Vazante. Conforme a tendência apresentada na figura 5, os picos máximos no rio Paraguai ocorrem entre os meses de Janeiro a Abril, quando o nível fluviométrico começa a decrescer. No período entre Maio e Julho o sistema está em transição ou no período de Vazante e entre Outubro e Janeiro no período de Enchimento, também de transição. Os meses de Agosto e Setembro configuram os períodos de maior vazante com nível máximo de $1 \mathrm{~m}$ registrado em 1966 e próximo a 2,5 m em 1986. Observa-se que nos anos de 1976 e 1996 o rio atingiu altura máxima no mês de Março, próximo aos $5 \mathrm{~m}$, fato semelhante ao ano de 1966, contudo a altura registrada ficou $1 \mathrm{~m}$ abaixo do valor supracitado. No ano de 1986 a altura máxima foi registrada no mês de Fevereiro com 4,5 m e em 2006 no mês de abril com $5 \mathrm{~m}$.

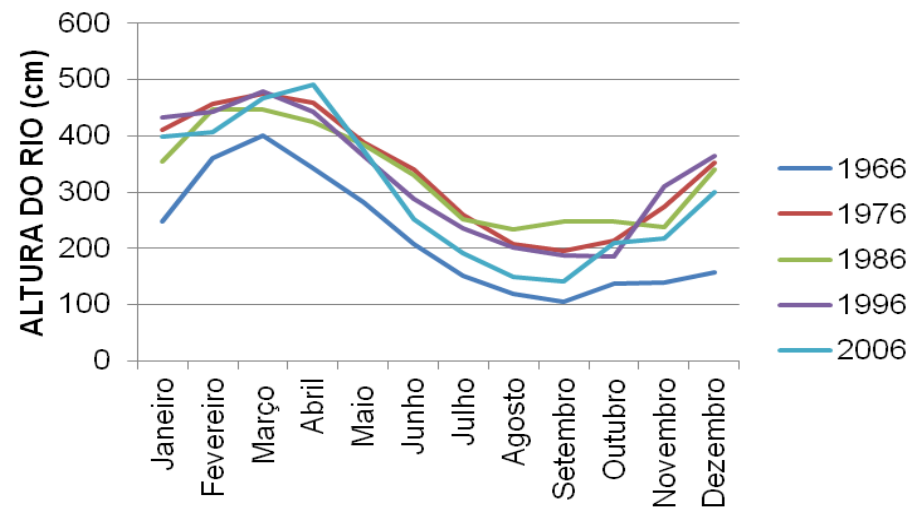

Figura 5. Dinâmica fluviométrica do rio Paraguai na Estação de Cáceres, Mato Grosso. Fonte: Dados obtidos junto Agência Nacional de Águas.

Org.: Gustavo Roberto dos Santos Leandro (2014).

De acordo com a análise dos dados, a média histórica dos valores totais de precipitação para o período de 39 anos na Estação Pluviométrica de Cáceres foi de 1314,7 mm. Na década de 1970 foram registrados os maiores picos quando comparados às demais décadas. Cabe salientar ainda que, houve oscilação no volume precipitado anualmente com significativa redução nas décadas posteriores. Os anos de 1990 foram marcados com a maior ocorrência anual acima da média. Na década de 2000 foram registrados os menores volumes anuais acima da média com destaque para 2006, 2008 e 2010 (Figura 6). 


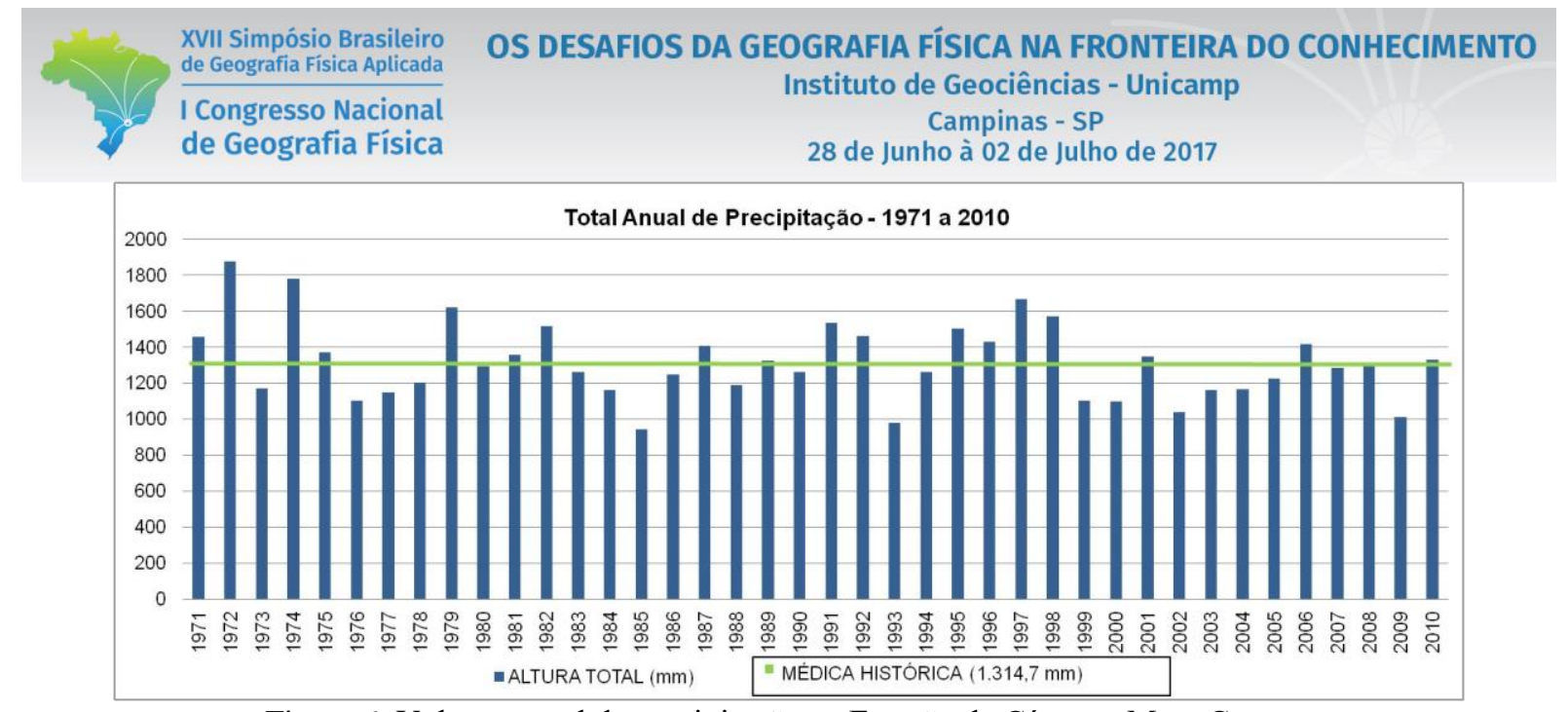

Figura 6. Volume anual de precipitação na Estação de Cáceres, Mato Grosso.

Fonte: Dados obtidos junto ao Instituto Federal de Mato Grosso, Campus de Cáceres.

Org.: Gustavo Roberto dos Santos Leandro (2014).

Ainda sobre o comportamento anual das chuvas da região Dallacort et al. (2014) mostraram que $38,7 \%$ dos anos (11 anos) ocorreram precipitação superior à média e que 61,3\% dos anos (19 anos) obtiveram precipitação inferior à média (período entre 1979-2009). Foi observado que 93,5\% dos anos (29 anos) apresentaram precipitações entre 1000 e $1500 \mathrm{~mm}$ e apenas 6,5\% dos anos, 1985 e 2002, assumiram precipitações inferiores a $1000 \mathrm{~mm}$. Salienta-se que, os dados analisados pelos autores correspondem ao período entre 1979-2009.

Os valores de mínima e máxima referente à vazão e precipitação correspondem aos índices do mês de determinado ano e, a média corresponde à soma dos 12 meses do ano. Quando comparados os valores máximos, mínimos e de média, se observa a amplitude da precipitação em Cáceres e Mato Grosso, o que é característico do clima regional com períodos de chuva e seco bem definido. O volume máximo precipitado no período foi superior aos $500 \mathrm{~mm} /$ mês em 1974 com oscilações ao longo do período. Os valores médios variaram entre $50 \mathrm{a} 150 \mathrm{~mm}$ no período com pico em 1972. Enquanto que, os volumes mínimos foram inferiores aos $40 \mathrm{~mm}$ com valor máximo registrado em 1991 (Figura 7).

Santos et al. (2012) argumentaram que a maior variação pluviométrica em Cáceres ocorreu entre as décadas de 1970 e 1980, pois houve uma redução de 135,7 mm de chuva em relação a média por décadas. Quando os autores compararam as décadas de 1980 e 1990 constataram que as chuvas aumentaram, pois a variação foi de $70,8 \mathrm{~mm}$. Entre as décadas de 1990 e 2000 verificaram novamente um declínio com variação de $108,3 \mathrm{~mm}$ no ritmo de chuva. No entanto, quando relacionaram a primeira e a última década analisada, notaram um declínio de 173,2 mm, por isso, concluíram que durante a década 2000, houve uma nítida redução das chuvas em relação à década de 1970 na região de Cáceres - Mato Grosso. 


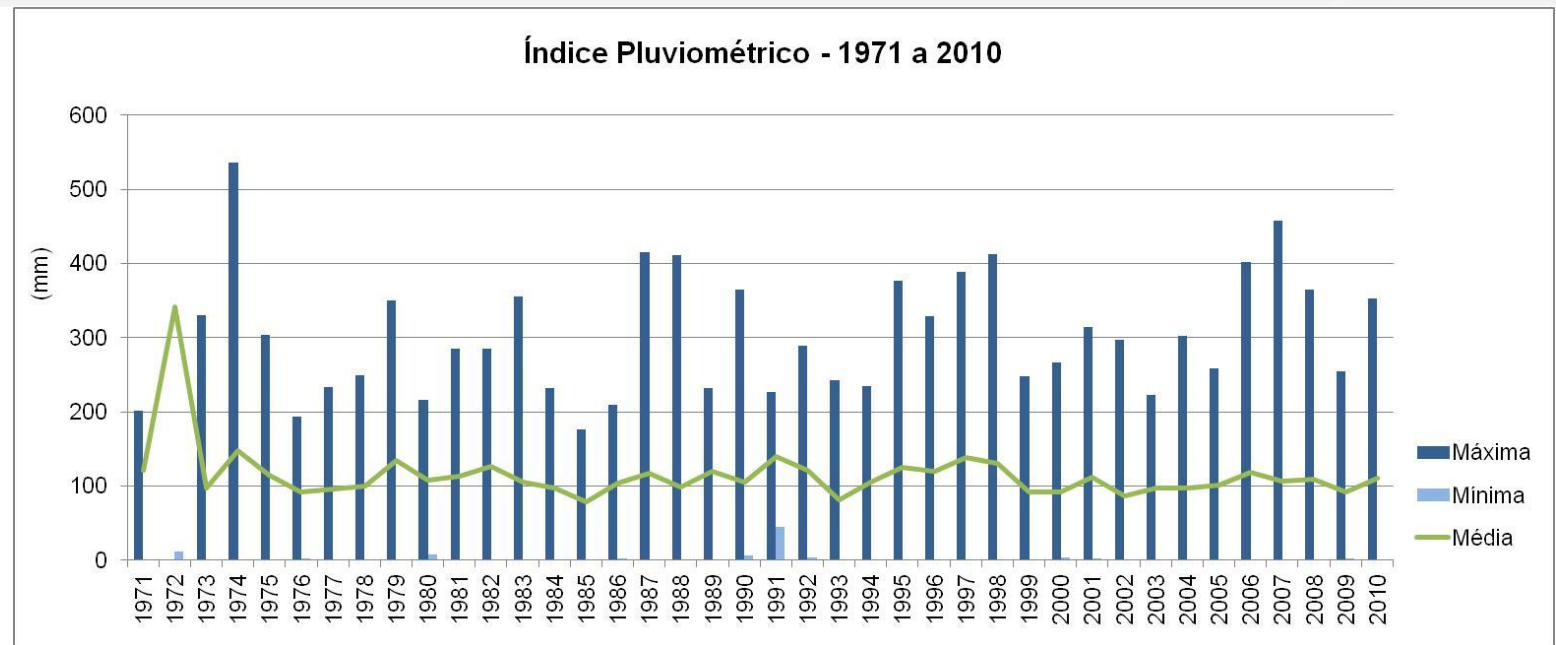

Figura 7. Valores pluviométricos na Estação de Cáceres, Mato Grosso.

Fonte: Dados obtidos junto ao Instituto Federal de Mato Grosso, Campus de Cáceres.

Org.: Gustavo Roberto dos Santos Leandro (2014).

Durante o início do período chuvoso na região sudoeste de Mato Grosso (que inicia em setembro) ocorre o armazenamento da água aportada por meio da precipitação. Neste momento o rio Paraguai ainda se encontra com níveis baixos e a descarga começa a aumentar conforme o fluxo de base aumenta. Dessa forma, os valores máximos de cheias ocorrerão apenas dois ou três meses após o período de precipitação mais intensa (GRIZIO-ORITA e QUEIROZ, 2013).

Leli et al. (2010) destacam que, apenas uma parte da água da chuva que ocorre sobre uma bacia escoa por sua superfície. $\mathrm{O}$ volume que é retido pela cobertura vegetal e evapora diretamente sem atingir o chão é denominado de água de interceptação. Outra parte, bastante pequena, denominada água biológica, atinge o solo e é absorvida pelas plantas e animais e não prossegue seu trajeto para o canal. E ainda conforme os autores, parte significativa do volume precipitado se infiltra no solo e segue seu caminho, muito mais lentamente, em subsuperfície. O restante do volume de água precipitado escoa pela superfície das vertentes e se concentra nos canais de drenagem.

O rio Paraguai atingiu picos máximos em Cáceres nos anos de 1980, 1982 e 1995 com altura superior a 6 metros. A partir de 1971 foi verificado um aumento na altura média até o ano de 1986, bem como oscilações entre os anos de 1981 a 1987, quando se observa a estabilização acima dos 3,5 metros. No período entre 1971 a 1998 há variações na altura mínima sendo registrado valor máximo em 1982. Contudo, a partir de 1999 ocorre a redução nos valores mínimos à exceção dos anos de 2002, 2003 e 2006 Com relação a altura máxima os anos de 2007 e 2010 merecem destaque para o período de 2000 a 2010, embora tenha sido abaixo de máximas em décadas anteriores (Figura 8). 


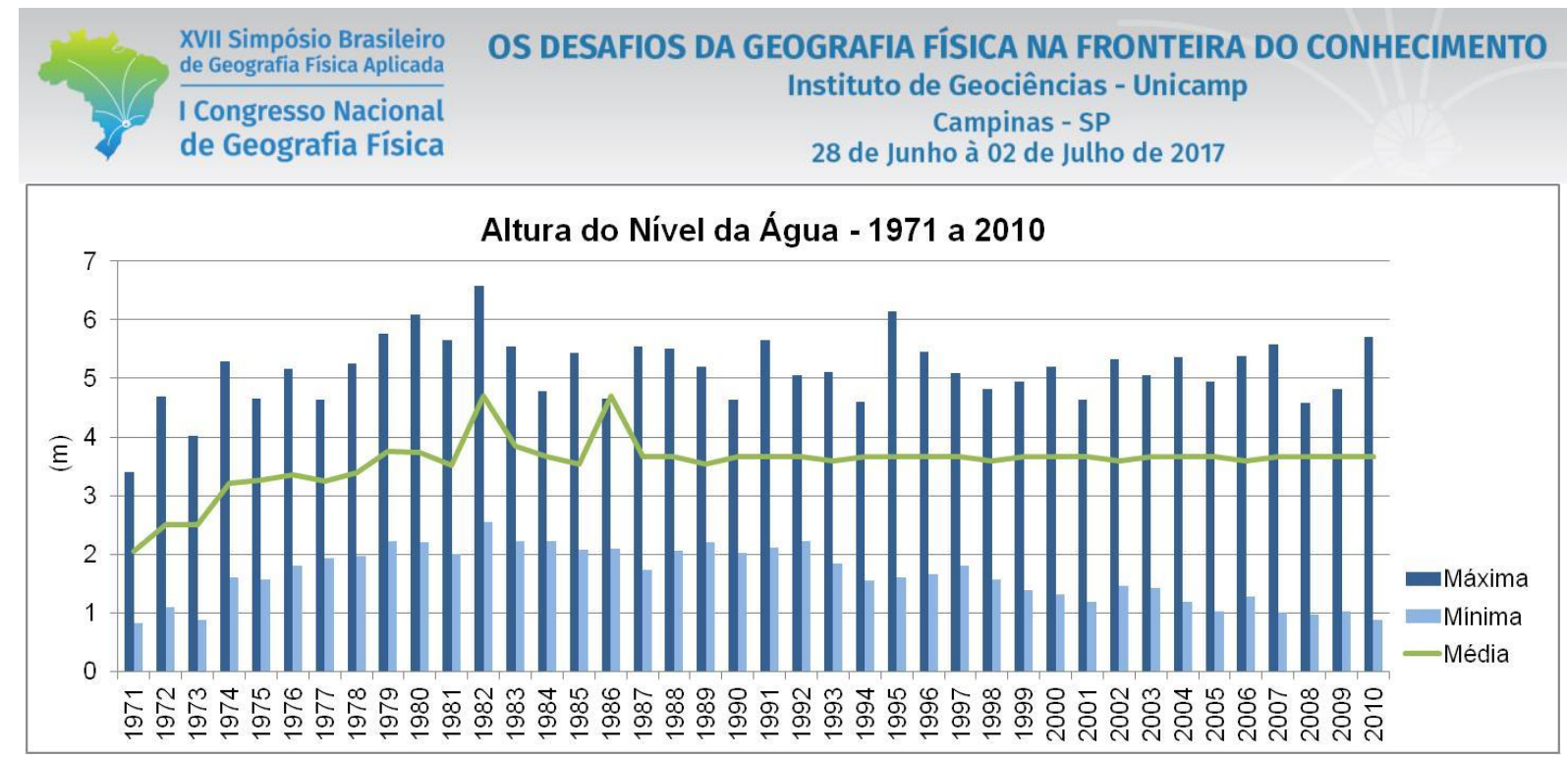

Figura 8. Amplitude fluviométrica no rio Paraguai na Estação de Cáceres, Mato Grosso.

Fonte: Dados obtidos junto a Agência Nacional de Águas.

Org.: Gustavo Roberto dos Santos Leandro (2014).

Nos anos de 2007 e 2010, a região de Cáceres foi atingida com algumas das maiores enchentes para o período de 2000 a 2010, resposta ao volume precipitado anteriormente e a saturação do lençol freático. $\mathrm{O}$ ritmo de enchimento e esvaziamento pode ser associado ao volume de água aportado de montante e em seus afluentes, ou seja, uma resposta lenta ao aumento de vazão. Os valores mínimos mantiveram similaridade enquanto que os picos apresentaram maior variação com destaque para os anos de 1980, 1982 e 1995 com valores elevados, bem como, os anos de 1971 e 1973 que registraram valores máximos abaixo da média dos anos posteriores. Os valores médios de vazão ocorreram com oscilações devido à soma da máxima e mínima registrada para cada ano, ou seja, os valores máximos exerceram forte influência sobre tais oscilações (Figura 9).

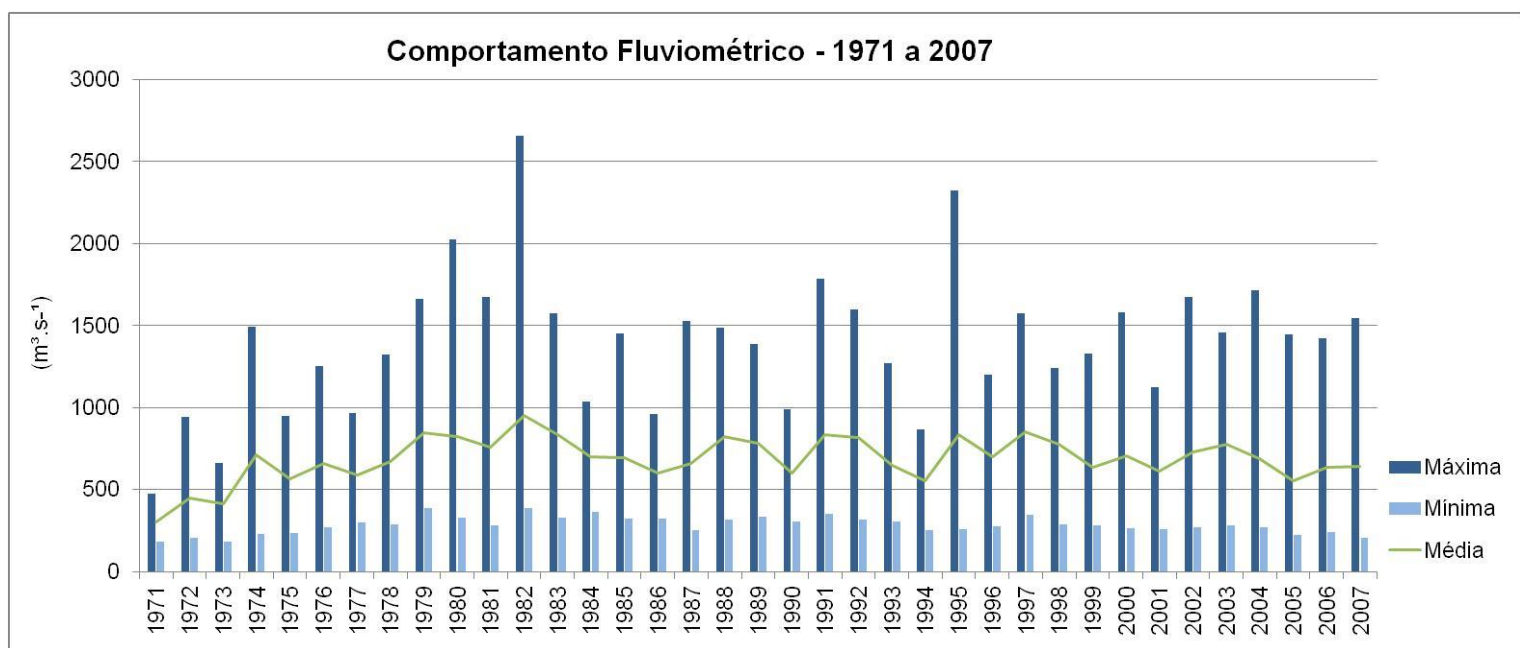

Figura 9. Amplitude da vazão do rio Paraguai na Estação de Cáceres - Mato Grosso. Fonte: ANA - Agência Nacional das Águas.

Org.: Gustavo Roberto dos Santos Leandro (2014). 
XVII Simpósio Brasileiro

de Geografia Física Aplicada

I Congresso Nacional

de Geografia Física

\section{OS DESAFIOS DA GEOGRAFIA FÍSICA NA FRONTEIRA DO CONHECIMENTO \\ Instituto de Geociências - Unicamp \\ Campinas - SP \\ 28 de Junho à 02 de Julho de 2017}

Santos (2013) correlacionou as enchentes ocorridas em 11 de fevereiro de 2010 na cidade de Cáceres-

MT ao transbordamento dos córregos que a cortam e em virtude dos 159,4 mm precipitados, o que, interferiu diretamente nos espaços ocupados pela população. O autor comparou os desastres naturais ocorridos ao ano de 1982 quando o transbordamento do rio Paraguai ocasionou problemas no abastecimento de alimentos e combustível em toda região. Conforme destacado pelo autor o rio Paraguai atingiu em 17 de março do corrente ano 6,58 metros, maior marca aferida pela Agência Fluvial de Cáceres-MT. Cabe salientar que, o pico de cheia ocorreu um mês após o volume máximo de precipitação registrado em Cáceres naquele ano (Figura 10).

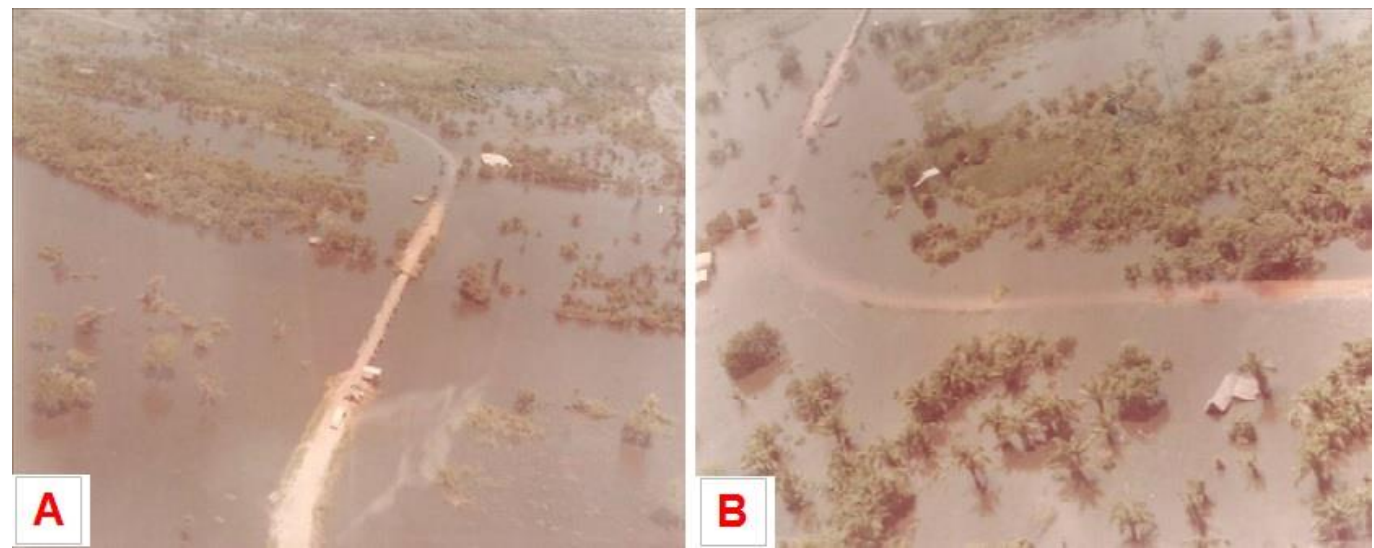

Figura 10. Trechos interrompidos da BR-070 próximo a Ponte Marechal Rondon em Cáceres, Mato Grosso. Fonte: Arquivos da Prefeitura de Cáceres - MT.

Conforme mencionado anteriormente, as enchentes registradas em 1982 e em 2007 e 2010 na região de Cáceres foram atribuídas ao volume precipitado e aporte de água nos afluentes. Contudo, os valores de precipitação e vazão para 2007 e 2010 foram inferiores aos registrados em 1982 embora elevados. Outro fator que pode explicar tais desastres é a mudança no uso e cobertura do solo. Isso porque, de 1980 em diante houve grandes alterações no sistema ambiental da bacia, sobretudo com a substituição da vegetação nativa por atividades agropecuária. No perímetro urbano de Cáceres a expansão da área de Influência aliada a impermeabilizações condiciona maior velocidade ao escoamento, ou seja, embora em menor volume ocorre em menor tempo.

\section{Considerações Finais}

As chuvas em Mato Grosso, típicas de Clima Tropical conforme classificação de Köppen, ocorrem em duas estações bem definidas, sendo Período Chuvoso e Período de Estiagem. Destaca-se ainda sua distribuição na bacia hidrográfica do Alto rio Paraguai. Os maiores volumes precipitam nas áreas elevadas com progressiva redução sentido Pantanal. Nesse contexto, as "Chuvas de Planalto" são 
fundamentais para a manutenção das características morfológicas e hidrodinâmicas no sistema canalplanície de inundação a partir da conexão entre seus ambientes e o pulso de inundação.

Ao longo do período de 40 anos foi verificado redução e aumento entre décadas sendo a dinâmica de variação bem expressa nos anos de 1971-1979 (volume acima da média com 1.414,4 mm), 1980-1989 (redução), 1990-1999 (aumento com média de 1.377,3 mm) e 2000-2010 (redução). Contudo, nos anos de 1982, 2007 e 2010 registrou-se algumas das maiores enchentes em Cáceres Mato Grosso. A diminuição do volume precipitado, contraditório as cotas fluviométricas registradas nos anos supracitados reforçam a importância das chuvas a montante e a relação entre Chuva-Geologia-Arranjo Geomorfológico (sistema em anfiteatro e amortecimento da planície aluvial).

Nesse sentido, um terceiro ponto a ser considerado é o processo de apropriação do relevo na bacia do Alto rio Paraguai intensificada nos anos de 1980. Os usos agropecuários se estendem por toda a faixa de cabeceiras e Depressão do Alto rio Paraguai. A conversão da cobertura vegetal em áreas de monoculturas e pastagem, podem alterar a aporte das águas superficiais, bem como de sedimentos para a planície pantaneira. Portanto, cabe serem repensados os modelos de produção e a importância das áreas de preservação e conservação, sobretudo ao longo dos canais fluviais e suas planícies de inundação que, são importantes ambientes de amortecimento.

\section{Agradecimentos}

Ao projeto "Processo de Sedimentação e qualidade da água no rio Paraguai no trecho entre a foz do rio Bugres e a Estação Ecológica da Taiamã - MT”, financiado pelo Edital MCT/CNPq/FNDCT/FAPs/MEC/CAPES/PRO-CENTRO-OESTE N ${ }^{\circ}$ 031/2010, pelo apoio financeiro que possibilitou os trabalhos de campo e a sistematização dos dados tratados neste artigo. À FAPESP - Fundação de Amparo à Pesquisa de São Paulo, pela concessão de Bolsa de Doutorado (2017-2019) ao primeiro autor. Também à Universidade do Estado de Mato Grosso (UNEMAT), pelo apoio logístico por meio do Laboratório de Pesquisa e Estudos em Geomorfologia Fluvial (LAPEGEOF) do Campus de Cáceres.

\section{Referências}

ANDRADE, R. G.; SEDIYAMA, G. C.; PAZ, A. R.; LIMA, E. P.; FACCO, A. G. Geotecnologias aplicadas a parâmetros biofísicos do Pantanal. Pesq. agropec. bras. Brasília, v. 47, n. 9, p. 1227-1234, 2012.

CAMARGO, L. (Org.). Atlas de Mato Grosso: abordagem socioeconômico-ecológica. Cuiabá - MT: Entrelinhas, 2011.96 p.

CLARKE, R. T., TUCCI, C. E. M.; COLLISCHONN, W. Variabilidade temporal no regime hidrológico da bacia do rio Paraguai. Revista Brasileira de Recursos Hídricos. v. 8, n. 1, p. 201-211, 2003.

COSTA, A. O.; SALGADO, C. M. DINALI, Y. T. Caracterização da precipitação no médio vale do rio Paraíba do Sul fluminense (RJ). Revista GeoNorte. v. 2, n. 5, p. 1000-1013. 2012. 
DALlACORT, R.; NEVES, S. M. A. S.; NUNES, M. C. M. Variabilidade da Temperatura e das Chuvas de Cáceres/Pantanal Mato-Grossense - Brasil. Geografia (Londrina). Londrina, v. 23, n. 1, p. 21-33, 2014.

GRIZIO, E. V.; SOUZA FILHO, E. E. As modificações do regime de descarga do rio Paraguai Superior. Revista Brasileira de Geomorfologia. v. 11, n. 2, p. 25-33. 2010.

GRIZIO-ORITA, E. V.; QUEIROZ, D. R. E. Tratamento gráfico de informação para vazão e precipitação utilizando a técnica de fichário-imagem. Boletim Paranaense de Geociências. v. 68, n. 69, p. 36-42, 2013.

LELI, I. T.; STEVAUX, J. C.; NÓBREGA, M. T. Produção e transporte da carga suspensa fluvial: teoria e método para rios de médio porte. Boletim de Geografia. v. 28, n. 1, p. 43-58, 2010.

NEVES, S. M. A. S.; NUNES, M. C. M; NEVES, R. J. Caracterização das condições climáticas de Cáceres/MT - Brasil, no período de 1971-2009: subsídio às atividades agropecuárias e turísticas municipais. Boletim Goiano de Geografia, Goiânia, v. 31, n. 2, p. 55-68, 2011.

PEREIRA, G.; CHÁVEZ, E. S.; SILVA, M. E. S. O estudo das unidades de paisagem no bioma Pantanal. Revista Ambiente. Água, Taubaté, v. 7, n. 1, p. 89-103, 2012.

SANTANA, M. F.; SOUZA, C. A.; OLIVEIRA JUNIOR, E. S. Análise de séries temporais de vazão e precipitação na bacia do rio Paraguai. Revista GeoPantanal, Corumbá, v. 8, n. 14, p. 67-89, 2013.

SANTOS, L. Pluviosidade, impactos naturais, percepção humana e as inundações em Cáceres/MT - 1971 a 2010. 2013. 133 f. Dissertação (Mestrado em Geografia) - Instituto de Ciências Humanas e Sociais, universidade Federal de Mato Grosso - UFMT, Cuiabá, 2013.

SANTOS, L.; ZAMPARONI, C. A. G. P.; SOARES, J. C. O ritmo pluviométrico na região de Cáceres-MT no período compreendido entre a série histórica de 1971 a 2010. Revista GeoNorte. v. 1, n. 5, p. 1091-1102, 2012.

SOUZA, C. A.; SOUSA, J. B. Pantanal mato-grossense: origem, evolução e as características atuais. Revista Eletrônica da associação Brasileira dos Geógrafos - Seção Três Lagoas - MS, Três Lagoas, v. 11, p. 34-54, 2010 . 